\title{
The Role of Ontologies through the Lifecycle of Virtual Reality based Training (VRT) Development Process: A Review Study
}

\author{
Youcef Benferdia ${ }^{1}$, Mohammad Nazir Ahmad ${ }^{2}$, Mushawiahti Mustafa ${ }^{3}$, Mohd Amran Md Ali ${ }^{4}$ \\ Institute IR4.0, Universiti Kebangsaan Malaysia, Bangi, Malaysia ${ }^{1,2,4}$ \\ Department of Ophthalmology, Faculty of Medicine Universiti Kebangsaan Malaysia, Kuala Lumpur, Malaysia ${ }^{3}$
}

\begin{abstract}
The size of learning content continually challenges education and training providers. A recent advanced technology called Virtual Reality (VR) has emerged as a promising choice to facilitate knowledge acquisition and skill transfer in a variety of sectors. The main challenge in this technology is the increasing costs, time, effort, and resources needed for designing Virtual Reality based Training (VRT) applications as educational content. To fill such gaps, ontology approach was introduced to support VR development. Therefore, this review has the objective of investigating on how ontologies have been applied throughout the life cycle of a VR development process. Accordingly, articles from the year 2015 onwards have been explored. Findings show that VR developers do not incorporate ontology in all phases of the lifecycle of VR methodology, but only cover some phases like creation and implementation. Creating novel solutions without a complete methodology results in a long development process and an ineffective product. This could consequently raise high dangers in real life, especially when VRT is for fields containing trivial details that are vital for saving lives such as healthcare. This research thus presents a proposal of methodological guidance on designing VR applications with the use of an ontology approach throughout all the life cycles of VR construction.
\end{abstract}

Keywords-Virtual reality; ontology; methodology; training and learning

\section{INTRODUCTION}

In today's world, people have been surrounded by sophisticated technology that forces them to live on the edge of a technological revolution. Consequently, it will fundamentally change their life in terms of the way they live, study, and communicate with one another. This revolution has created new services and products in order to make their life easy. Nowadays many services can be remotely provided including ordering food, grab car, booking a flight, and training.

The VR, for example, is one of important enabling technologies for 4IR. It has increasingly attracted many researchers in several application domains such as social media, education, culture heritage, entertainment, training and healthcare. This technology "provides an immersive multimedia 3D simulation of real life, supports interactivity with the created environment and enables sensorial experiences" [1]. The immersive environment can be similar to the real world or it can be fantastical, creating an experience not possible in ordinary physical reality. VR has become a prevalent application in a variety of domains such as entertainment, tourism, e-commerce, education, and training. Recently it is most commonly used for the training and learning environment. VR offers important benefits by providing flexible and efficient training processes, which notably result in cost reduction and the removing of any risk associated with training in real environments.

Even though VR applications is not truly a new technology, its development is still in the earlier stages. The successful rate of its adoption in education for example, is not well reported in the literature [2]. Some reasons for that may be the cost [3], [4]; lack of understanding and capturing training scenarios and learning contents in an explicit manner, and so on [4], [5]. Besides that, VR is very knowledge-intensive. For example, capturing knowledge on the "know-how" among domain experts, conducting different training scenarios, where the absence of any details can lead to serious problems. Additionally, [3] the development process for the training and learning discipline is a tedious task and needs a long development life cycle, due to the much knowledge-intensive task and complex area required to be dealt with. To simplify a VR implementation, there is a requirement to have a modelling tool.

Ontology, in this context, is introduced to design a standardized conceptualization model at a high level of abstract and expressiveness with the purpose of offering a shared and common understanding of the domain. This tool can capture and represent training scenarios and the activities taking place in a Virtual Environment (VE) in an expressive manner. Unfortunately, in spite of the fact that ontology is developed for VRT in a variant of domains such as healthcare as reviewed in [6], presently, the existing VRT development methodologies do not pay much attention to having knowledge-based models explicitly, throughout the VR development life cycle. Designing ontology-based Unified Foundation Ontology (UFO), for example, is a significant step which models a large domain world that consequently makes it highly reusable across different domains. The underlying logic for adopting and generating foundation ontology, according to [7], is mainly to have a minimal collection of particular and generic concepts including key terms, proprieties, potential axioms and relationships. These concepts play a role as common knowledge, describing the real world, which significantly facilitates the extending and reusing of tasks that essentially promise the adoption across all domains. For example, 
ophthalmology domain consists of many diseases such as cataract, glaucoma and so on. Let us assume that the ontology for cataract surgery has already been designed. If any ontology engineer wishes to design an ontology for glaucoma disease, they need to only use the existing one and extend it with the process of glaucoma surgery, because the domain knowledge is already there. Hence, as it is obvious that designing ontology for cataract domain provides many possibilities to reuse it several times in order to make a huge ontology that can cover the whole ophthalmology domain. Therefore, selecting the right upper ontology and its language is highly recommended. This would help promote the effectiveness of reusing an existing ontology, which would assist in drastically avoiding any redundant efforts and time spent for building up new virtual training scenarios.

Heaving in hand, guideline and user-friendly tools for ontological engineers, VR developers and domain experts throughout all phases of the VR development life cycle, this becomes critical to benefit the reduction of the needed time, costs, and efforts. The consequently leads to promoting VR adoption. This guideline is proposed to guarantee the systematic rigor in the designing and evaluation of VR application. Therefore, this paper attempts to answer the following question:

Q1. How is ontology used through the lifecycle of a VR development methodology?

The remnant of this paper is arranged as follows: Section II provides a brief definition of the ontology and describes the significant roles of ontologies for VRT. In Section III, research methods for selecting the primer studies are discussed. The results of this review are presented in Section IV. In Section V, a critical discussion on the findings is presented, Finally, Section VI presents the paper's conclusion and the new proposed guidance methodology.

\section{LITERATURE}

A classic definition of ontology is "an explicit specification of a conceptualization" [8]. The conceptualization is an abstract simplified view of some selected part of the world (portion of a reality), containing concepts and their relationships between them. It exists on a community's mind as shared knowledge. The community members in this case are doctors, youths, VR experts and other stakeholders. An explicit specification of a conceptualization is an ontology, which is a conceptual model (knowledge-based model) and has been identified as a prominent tool to represent shared knowledge explicitly [9] [10]. Feilmayr \& Wöß [11] recently defined ontology as "A formal, explicit specification of a shared conceptualization that is characterized by high semantic expressiveness required for increased complexity". This means that ontology is an abstract of a selected part of the world, which is unambiguously represented using a formal language. This representation should have high semantic expressiveness, should be shared among a variant of the stakeholders, and restricted to a definite domain of interest.

The training scenario and the learning content are the core part in any VRT application. The knowledge for this comes from domain experts in a particular area. Capturing high semantic and expressive training scenarios, on know-what and know-how, are crucial for an ideal VRT domain. Thus, in order to capture and represent this knowledge in sequence and in a coherent manner, ontologies were applied to a number of projects of VRT in a variety of fields. For example, in the Smart Home Simulator (SHS) project by Baldassini et al. [12], ontology was used to provide elder people a system, enabling them to follow a healthy lifestyle. It was applied to manage all heterogeneous data (e.g., devices, users, and environments). In order to ensure that users were following the suitable activities at home, a reasoning process was also enabled to query the desired data. BKOnto [13] was developed to support a virtual exhibition system, which was built based on biographical history. The aim of ontology here was to assist virtual presentation by offering structure descriptions and definitions that explicitly present the historical materials, places, and events. This ontology behaved as a storyline that enabled users to easily navigate a semantic web with the help of VR technology. Walczak and his colleagues [14] proposed a new approach in developing a VR training scenario for electrical operators with a help of ontology. They utilized two technologies including semantic web technology and VR Scenario Editor (VRSEd) application in order to facilitate knowledge representation. Finally, Liang and his team [15] attempted to develop a semantic framework to design collaborative animation for project art as shadow puppetry. This approach helped to minimize the intensive efforts and a long process for designing VRT application. It also assists to enhance the reusability of animation properties.

\section{METHOD}

In order to reach the objective of this research, an inclusive review method of published papers up to the year 2021 was conducted. Some key features of the SLR methodology were applied to support this study. The main objective of this review is to investigate how the proposed ontologies for VRT in general areas have been utilized to support the phases of VRT development methodology. At the first stage, therefore, a set of keywords were firstly applied in electronic bases in order to retrieve the first collection of papers. Accordingly, a variety of electronic databases were used including Science Direct, Springer, ACM, Web of Science, Emerald, Taylor \& Francis, IEEE Xplore Digital Library, Wiley Online, and Google Scholar. As a result, the first set of papers were retrieved based on titles. During the Step 2, duplicated studies were removed using either Mendeley software or manually. In Step 3, keywords and abstracts were reviewed and papers were excluded when the inclusion criteria were not met. Abstracts with insufficient data were left to the next step. The complete text of extracted studies were analyzed in Step 4 using inclusion and exclusion criteria. These criteria were applied to extract the most relevant papers. Thus, the criteria were reviewed to include:

- Published studies between January 2015 and July 2021 were included.

- The articles included were related to ontology using VR for training and learning. 
- Studies were excluded if they had been written in a language other than English, OR.

- Their designed ontology was focused in representing $3 \mathrm{D}$ content such as appearance, and geometry logic.

\section{RESULT}

After the premier studies were selected, the articles were ready for the analysis and synthesis task. The next sections give summary descriptions of the proposed ontologies and their roles in the VR development process.

\section{A. The Designed Ontologies in different Domains}

In the following sections, a short description of each ontology in various sectors is provided along with an indication of the most significant design components such as methodology for developing ontology, tools, language, and so on (see Table I).

TABLE I. THE DESIGN COMPONENT OF ONTOLOGY AND ITS NATURE OF IMPLEMENTATION

\begin{tabular}{|c|c|c|c|c|c|c|c|}
\hline \multirow{2}{*}{ Reference } & \multirow{2}{*}{ Ontology Name } & \multirow{2}{*}{ Area } & \multicolumn{4}{|l|}{ Design Component } & \multirow{2}{*}{ Evaluation } \\
\hline & & & Type of ontology & Language & Tool & Methodology & \\
\hline $\begin{array}{l}\text { Walczak et al. } \\
{[14]}\end{array}$ & $\begin{array}{l}\text { Ontology for } \\
\text { VRSEd project }\end{array}$ & Industry & Domain ontology & RDF, RDFS and OWL & NM & NM & Yes \\
\hline $\begin{array}{l}\text { Tielman et al. } \\
{[16]}\end{array}$ & $\begin{array}{l}\text { Ontology for } \\
\text { virtual coach }\end{array}$ & Healhacre & Domain ontology & Class diagram & NM & NM & Yes \\
\hline $\begin{array}{l}\text { Heyse et al. } \\
{[17]}\end{array}$ & $\begin{array}{l}\text { Ontology for VR } \\
\text { Exposure Therapy } \\
\text { (VRET) }\end{array}$ & Healhacre & $\begin{array}{l}\text { Upper and domain } \\
\text { ontology }\end{array}$ & Use case diagram, DL & NM & Co-design method & NM \\
\hline $\begin{array}{l}\text { Antoniou et al. } \\
{[18]}\end{array}$ & ENTICE ontology & Healhacre & Domain ontology & $\mathrm{RDF}$ & NM & NM & NM \\
\hline Dris et al. [19] & IVE ontology & Industry & Domain ontology & OWL & Protégé & Noy \& McGuinness & Yes \\
\hline $\begin{array}{l}\text { Vincent et al. } \\
{[21]}\end{array}$ & Inoovas ontology & Industry & Domain ontology & UML & NM & NeOn Methodology & Yes \\
\hline $\begin{array}{l}\text { Filho et al. } \\
\text { [22] }\end{array}$ & $\begin{array}{l}\text { Ontology for } \\
\text { operator } \\
\text { training simula-tor } \\
\text { scenarios }\end{array}$ & Industry & Domain ontology & OWL-DL & Protégé & MCCA & Yes \\
\hline $\begin{array}{l}\text { Elenius et al. } \\
\text { [23] }\end{array}$ & SAVE & Industry & Domain ontology & Flora2 & Sunflower & NM & Yes \\
\hline $\begin{array}{l}\text { Liang et al. } \\
{[15]}\end{array}$ & $\begin{array}{l}\text { Ontology for } \\
\text { virtual shadow } \\
\text { play performance }\end{array}$ & Art & Domain ontology & OWL SWRL & Protégé & NM & Yes \\
\hline $\begin{array}{l}\text { Yeh and } \\
\text { Huang [13] }\end{array}$ & BKOnto & Art & Domain Ontology & OWL & NM & NM & NM \\
\hline $\begin{array}{l}\text { Dragoni et al. } \\
\text { [25] }\end{array}$ & PRESTO Ontology & Healthcare & Upper ontology & OWL & NM & NM & Yes \\
\hline $\begin{array}{l}\text { Baldassini et } \\
\text { al. [29] }\end{array}$ & $\begin{array}{l}\text { Ontology for SHS } \\
\text { project }\end{array}$ & Healthcare & Domain Ontology & RDF, OWL & NM & NM & Yes \\
\hline
\end{tabular}

1) Ontology for VRSEd project: Walczak et al. [14], in their work proposed a new method in designing a VR training scenario for electrical operators with the help of semantic web technology. The latter technology enables knowledge representation. Both semantic modeling approach and the user-friendly VRSEd application were implemented as an expansion to Microsoft Excel. Domain experts were enabled to build training scenarios utilizing domain concepts defined by ontologies. RDF, RDFS and OWL standards were used to implement the scenario ontology. However, the tool and methodology are not mentioned in this paper. The new method was implemented and demonstrated as a desktop application for developing VR scenarios, which was further evaluated by domain experts.
2) Ontology for virtual coach: In Tielman et al. [16]'s work, an ontology-based question system was built in order to support a virtual coach. The latter technology was used to provide self-therapy for post- traumatic stress disorder patients, which enables patients to follow therapy at their own home. The vital side of this therapy is on how to assist patients in recollecting their traumatic memories. Ontology, therefore, was applied to support a dialogue system in virtual coach, where it was utilized to capture and represent knowledge and meaning of the real domain (see Fig. 1). In this paper, the ontology is presented using a class diagram, whereas methodology and tool are not mentioned. The ontology based system was evaluated using a within-subject experiment in order to confirm the performance of the ontology in helping patients to recollect their lost memories. 




Fig. 1. Ontology of Holiday Moment Locations [16].

3) Ontology for VR exposure therapy (VRET): In this project [17], semantic ontology was designed with the purpose to model the necessary knowledge (e.g., concepts and relation) in a way to represent the domain of anxiety therapy in VE. The aim of the designed ontology was also to provide semantic reasoning in order to deduce essential knowledge from low-level data in VRET. This can be archived by using Description logic (DL) language, which permits to formulate such rules. The use case diagram was utilized to represent the proposed ontology which contains three layers of ontologies including foundation, domain, and application ontologies. The co-design method was applied to design the project's ontology, while a tool was missed in this study. The integration of the ontology inside VE and its evaluation was left to further work.

4) ENTICE ontology: The aim of immersive educational technology including Augmented, Virtual and Mixed Reality (VR/AR/MR communally XR), is to facilities skills acquisition and knowledge retention in the healthcare field. Designing XR immersive educational content is considered as the core challenge in terms of cost, effort, time, and resources required for developing. Therefore, Antoniou et al. [18] proposed an approach including the ENTICE ontology to enhance the content development and to facilitate the XR development process such as digital asset discoverability and reusability through visual authoring tools. The medical ontology terms were represented by using RDF. The integration of ontology into the XR environment and evaluation were planned as further research. The tool and methodology were not indicated in this project.

5) Interactive virtual environment ontology: Dris and his colleagues [19] in their work tried to propose an ontology that can help improve the use of Building Information Modeling (BIM) models as a Virtual Interactive Environment (VIE) generator. BIM is considered an approach that helps minimize the time spent in designing $\mathrm{VE}$ as a model for providing realistic 3D VE in the construction sector. In order to design this ontology, authors reused IFC (Industry Foundation Classes) ontologies [20] as the first step. The role of IFC ontology is to discover any possible incident of each fault that can be performed by modifying, adding, or removing objects inside the VE. Noy \& McGuinness's methodology, Protégé software, and OWL were the ontology engineering components used to build this ontology (see Fig. 2). Three sheets of questionnaires were designed to evaluate the ontology's effectiveness. The first was conducted prior to training so as to classify the trainees in terms of knowledge and technology. The second was done after training to evaluate knowledge acquisition. Lastly, a month later, the same questionnaire was provided to them again.

6) Inoovas ontology: The Inoovas ontology was designed by Vincent et al. [21]. Its aim is to solve the problem of how all resources including people (mechanical or electrical designer, IT maintenance), heterogeneous software, and tools (VR, AR) can work together, when they remotely join in the procedure with an effective data exchange method in an Augmented and Virtual Reality (AVR) environment. Inoovas ontology represents the knowledge base of the company which contains three important parts. Fig. 3 presents the Real Thing that describes the physical parts of the system, data exchange with the system, and other classes of managing requirements on the system. Twin Thing represents the 3D model of the system. Lastly, Real and Twin Thing ontologies concerns with defining AR classes. Vincent et al. [21] used UML to represent the classes involved in the ontology. This paper used $\mathrm{NeOn}$ methodology, where the editor tool was missed in this paper. Inoovas was evaluated by developing an application named MProd. This application is grounded on the Inoovas ontology concepts and properties.

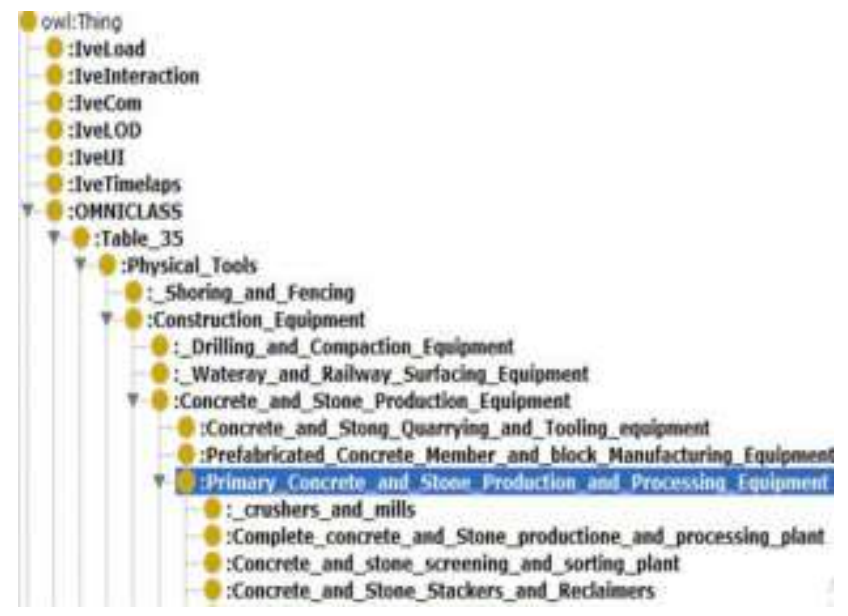

Fig. 2. Ontology OpenBIM based IVE Ontology- Extraction from Protégé [19].

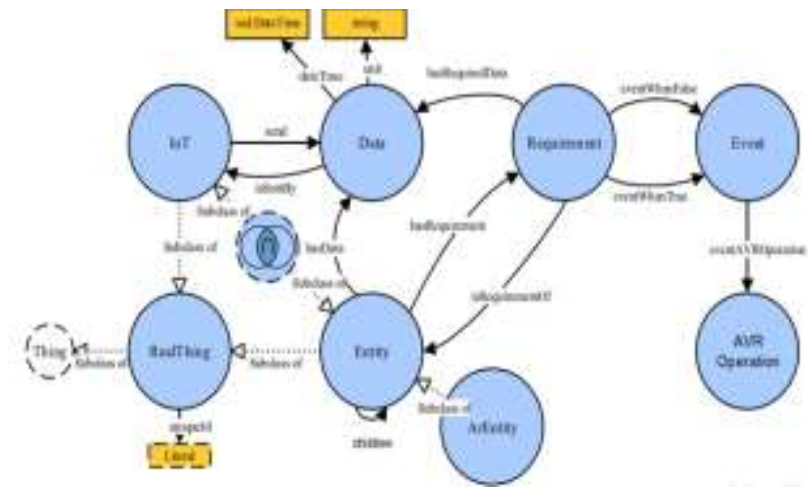

Fig. 3. Inoovas Ontology [21]. 
7) Ontology for operator training simulator scenarios project: This ontology is about designing error and training scenarios for electrical power system operators. The scenarios were developed according to accident reports (consisting of human error scenarios). According to this study, the construction of simulator training scenarios had posed various challenges. Dealing with multidisciplinary team of experts could cause several obstacles including producing implicit training scenarios and sharing a lack of knowledge among team members. Filho et al. [22] attempted to build an ontology that facilitates the development process of training scenarios and enhances common language sharing among stakeholders. The OWL-DL language was used to design ontologies, with the help of the Protégé tool. Incident Scenario Conceptual Model (MCCA) was the applied method to develop the ontology of this study. The designed ontology consists of two ontologies: training and error scenario ontology. A case study was the validation pathway to evaluate the ontology-based correctness and completeness of the terms.

8) SAVE ontology: Elenius et al. [23] designed a framework called Semantically Enabled Automated Assessment in Virtual Environments (SAVE). This ontology tries to provide an automated approach by using the semantic method. This helps describe or facilitate the action, event and rules including disassembling and assembling a Rifle. SAVE ontology reused Sunflower, which is an integrated development environment for ontologies and rules. Sunflower has a set of libraries and tools based on the Flora 2 language, which is a fully expressive language. Its root is based on OWL in descriptive languages. SAVE uses four components, namely, an ontology of components (physical objects), rules for creating components (and their sub-components), an ontology of actions, and rules for performing actions on components. However, the adoption methodology in this project again was not declared. In the evaluation part, all ontology models were tested by Subject Matter Experts (SMEs).

9) Ontology for virtual shadow play performance: In the VR domain, designing interactive animation is still a challenge and is labour-intensive. The reason for this is that during the development process many functional requirements need to be handled including massive data assets management, graphics, physics, etc. The purpose of Liang and his team [15]'s work was to design a semantic framework to develop collaborative animation for classical shadow play art (shadow puppetry). In the same way, it enables prompting reusability of animation properties. As a result, the development process was facilitated and extended. Two specific ontologies were built. The first one is Hand- and Gesture-Based Interaction Ontology (HGBIO) (see Fig. 4), and the second one is Digital Chinese Shadow Puppetry Assets Ontology (DCSPAO).

Having OWL enables integration of SWRL rules, which can be represented by utilizing SPARQL queries. The feasibility verification of ontology was performed using user experience tests of the ontology. At first, more descriptions of the operation of the system and 15 minutes of training were delivered to seven users. Then they were separated into two groups in order to conduct a qualitative test. The first three users tested ontology-based assets retrieval, while the other four users who were young children, examined the interaction comfort. As a result, both groups provided positive feedback regarding retrieval of material from animation resources, freedom of movement, ease of use, and naturalness.

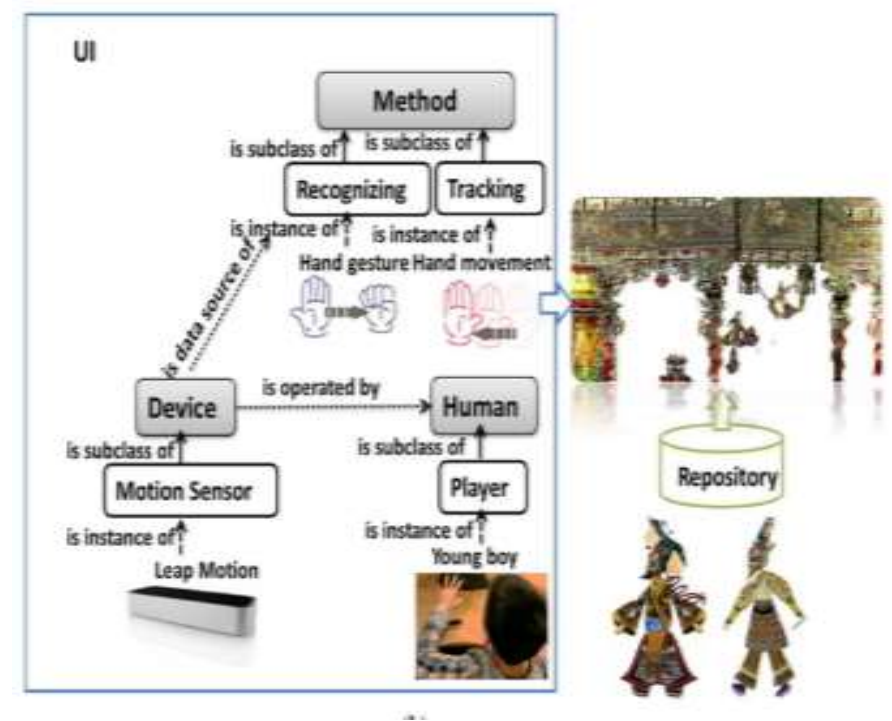

Fig. 4. Hand- and Gesture-based Interaction Ontology [15].

10)BKOnto ontology: Yeh and Huang [13] developed a virtual exhibition system based ontology knowledge. This ontology was designed based on biographical history, which is called BKOnto. The ontology's aim is to provide basic knowledge to assist virtual presentation. This ontology behaves as a storyline while assisting to provide structure definitions that systematically present the historical materials and events. BkOnto used the OWL mark-up language to describe cognitive knowledge bias for biographical historical material. This was further transformed into a VR exhibition space, which enabled users to easily navigate semantic structure in the form of a 3D space. This form can be reused in museums as a virtual exhibition that facilitates to manage several historical materials of semantic structure through the internet and provides visual experiences of a temporal event for internet users. The tool, methodology, and validated design of BkOnto were not indicated in this study.

11)PRESTO ontology: The PRESTO ontology was designed by Dragoni et al. [24] for the PRESTO (Plausible Representation of Emergency Scenarios for Training Operations) project. This project tried to describe the behaviour of an artificial agent into VE. Thus, the purpose of this ontology is to facilitate the development of a VR scenario and a character behavioral model. It enhances the source code's reusability, whereas the VR developers are plugged to a variety of source coding and underlying 3D-libraries. OWL language and lightweight ontologies were used to enhance semantics and provide explicit descriptions of existing 
scenarios in a VR environment. DOLCE, as top level ontology, was applied to select the entities of a VR scenario. However, tools and methodology were not clarified in this study. For validation purposes, modellers, and developers were interviewed to evaluate the effectiveness and usefulness of the designed ontology-based system.

12) Ontology for smart home simulator project: Baldassini and his colleagues [12] presented an ontology for the Smart Home Simulator project (SHS). The main challenge was the ability to provide elder people a system that could enable them to follow an active and healthy lifestyle. Basically, the ontology was used to manage all heterogeneous data regarding users, surrounding devices, and environments. The reasoning tools in this conceptual model enable a query process that provides the desired data to ensure that users follow the proper activities. The designed ontology relies on three ontologies that are based on several languages. These languages are RDF and OWL. The ontology components, just like tools and methodology, were not clarified. Task-based evaluation was applied to check the usability and ergonomics of the system. A number of healthy subjects (from 25 to 30 years old) were used. The aim of this kind of evaluation is to test whether the intended tasks have been achieved or not.

13)VEULMoR ontology: Designing VR applications for upper limb motor rehabilitation is a difficult task. Designers are required to master various aspects including strokesurvivor, characteristic motor rehabilitation, interaction devices, and so on. Therefore, Ramírez-Fernández et al. [25] designed the VEULMoR ontology. The proposed ontology helped capture domain expert knowledge and presented it into the ontology. This approach shortened the time and facilitated the development of VR applications. The VEULMoR ontology was designed with the help of the Protégé editor, Methontology methodology and the use of the OWL language. The evaluation was implemented with therapists and patients in terms of patient safety and the administration of therapy.

\section{B. Role of Ontology through the Life cycle of VRT}

TABLE II shows how ontology is applied in each phase of the life cycle of a VR development methodology. The phases are adopted from the work reported in Polcar et al. [26]. This methodology is only chosen because it covers all the phases of the life cycle of developing VR; as such, this entirely enables an illustration of the role of ontology. The description related to each phase is provided as follows:

- Assignment Phase: In this phase, the domain experts and ontology engineers work together in order to design Ontology Requirement Specifications Documents (ORSD) that include defining the goal and the scope of designing the ontology, the intended end-users, and develop competency questions. The answering of competency questions and other requirements in ORSD assists in extracting the overall concepts of the VR application in terms of requirements and wishes, which helps to design a robust training scenario with high fidelity.

- Analysis Phase: This phase cares about the output of the previous phase, including the extracted concepts and other collected knowledge form relevant documents and observations. This knowledge should be analyzed to get the foundation upon which the overall concepts of the VR application are built. In the same way, all objects with similar or same functions and appearance should be classified. The result of this phase can include common and shared knowledge, glossaries of terms, list of actions and objects, and a story board of the detailed scenario.

- Creation Phase: In this stage, the ontology model is completely designed to be used through the rest of the VR's phases. Ontology becomes the major guiding force which assists the VR developer in selecting the right objects, properties, and level of detail. This phase is mainly concerned about constructing the assets of VE including scripts, texts, graphics, animations, sounds, and hardware. Some assets can be created according to the ontology model as well.

- Testing Phase: Coordinated validation and verification are conducted by SME and IT experts to check the connection between the first prototype of VR to the ontology model in terms of 3D graphical objects, tasks, terms, concepts and so on.

- Implementation Phases: The transformation of the ontology from a visual model (e.g., conceptual model) to implementation mode (e.g., OWL, Java) helps VR development in terms of providing decision making, exchanging of data, retrieving information and so on. The finished product (the integration of ontology within VR) will be verified by domain experts.

- Operation Phase: This is the end point where the ontology model is used as a reference to compare the intended objectives with the observed results. In this stage, VR designers and SMEs make a systematic verification of the ontology and $3 \mathrm{D}$ by inviting end users to evaluate the utility of the artefact, for maintenance purposes, in order to suggest future extending and verification.

It is obvious that the role of ontology is messed or misused throughout the phases of the lifecycle of the VR development methodology. A majority of the ontology engineers focus only in some phases like analysis, creation, and implementation. To conclude from above table, VR methodology does not incorporate ontology in all phases of its lifecycle.

Regarding the misuse of ontology, there should be a call for more attention to address this matter and give further guidance on how designers should apply ontology throughout all phases of VRT development. In the next section we will try to address these challenges and fill the gaps. 
TABLE II. The Role of ONTOLOGY THROUGHOUt THE LIFECYCLE OF A VR DEVELOPMENT METHOdOLOGY

\begin{tabular}{|c|c|c|c|c|c|c|}
\hline \multirow[b]{2}{*}{ Authors } & \multicolumn{6}{|l|}{ Phases of VR } \\
\hline & Assignment & Analysis & Creation & Testing & Implementation & Operation \\
\hline $\begin{array}{l}\text { Antoniou et } \\
\text { al. [18] }\end{array}$ & $\begin{array}{l}\text { Create a } \\
\text { brainstorming } \\
\text { deliverable }\end{array}$ & $\begin{array}{l}\text {-To describe the } \\
\text { related terms } \\
\text { - To use Knowledge } \\
\text { Organization System } \\
\text { (SKOS) }\end{array}$ & $\begin{array}{l}\text { - Using RDF to design } \\
\text { ontology } \\
\text { - Using ontology as a reference } \\
\text { to develop some assets for VR }\end{array}$ & NM & NM & NM \\
\hline $\begin{array}{l}\text { Walczak et } \\
\text { al. [14] }\end{array}$ & $\mathrm{NM}$ & $\mathrm{NM}$ & $\begin{array}{l}\text { Using RDF, RDFS, and OWL } \\
\text { to design ontology }\end{array}$ & NM & $\begin{array}{l}\text { - Integrating ontology } \\
\text { inside VR application }\end{array}$ & $\begin{array}{l}\text { Verified by domain } \\
\text { experts }\end{array}$ \\
\hline $\begin{array}{l}\text { Hyse et al. } \\
\text { [17] }\end{array}$ & $\begin{array}{l}\text { - To collect the } \\
\text { essential } \\
\text { knowledge } \\
\text { - To define the } \\
\text { scope of ontology } \\
\text { - To create a list of } \\
\text { competency } \\
\text { questions }\end{array}$ & $\begin{array}{l}\text { - To determine the } \\
\text { most relevant } \\
\text { knowledge by } \\
\text { conducting } \\
\text { workshops }\end{array}$ & & & $\begin{array}{l}\text { - Integrating ontology } \\
\text { inside VR application }\end{array}$ & NM \\
\hline $\begin{array}{l}\text { Teilman et } \\
\text { al [16] }\end{array}$ & NM & NM & $\begin{array}{l}\text { - Using class diagram to design } \\
\text { ontology }\end{array}$ & NM & $\begin{array}{l}\text { - Implemented in VR } \\
\text { system }\end{array}$ & $\begin{array}{l}\text { Ontology based system } \\
\text { was evaluated by } 24 \\
\text { healthy participants }\end{array}$ \\
\hline $\begin{array}{l}\text { Dris et al. } \\
\text { [19] }\end{array}$ & $\begin{array}{l}\text { To determine the } \\
\text { domain and the } \\
\text { scope of the } \\
\text { ontology }\end{array}$ & $\begin{array}{l}\text { Conducting } \\
\text { acquisition of } \\
\text { knowledge to select } \\
\text { the main terms from } \\
\text { documents, } \\
\text { standards and the } \\
\text { existing risk hunting } \\
\text { courses }\end{array}$ & $\begin{array}{l}\text { - Using OWL to design } \\
\text { ontology } \\
\text { - Using ontology as a reference } \\
\text { to develop some assets for VR }\end{array}$ & NM & $\begin{array}{l}\text { - Integrating ontology } \\
\text { inside VR to improve } \\
\text { interoperability }\end{array}$ & $\begin{array}{l}\text { The utility of VR with } \\
\text { ontology was evaluated } \\
\text { by trainees }\end{array}$ \\
\hline $\begin{array}{l}\text { Vincent et } \\
\text { al. [21] }\end{array}$ & $\mathrm{NM}$ & $\begin{array}{l}\text { Getting concepts } \\
\text { from experts and } \\
\text { guidance procedures }\end{array}$ & $\begin{array}{l}\text { - Using UML to design } \\
\text { ontology } \\
\text { - Using ontology to create } \\
\text { some assets for VR }\end{array}$ & NM & $\begin{array}{l}\text { - Integrating ontology } \\
\text { inside VR to exchange } \\
\text { data, in an } \\
\text { interoperable way }\end{array}$ & $\begin{array}{l}\text { Application based } \\
\text { evaluation was conducted } \\
\text { to evaluate the ontology } \\
\text { effectiveness }\end{array}$ \\
\hline $\begin{array}{l}\text { Filho et al. } \\
{[22]}\end{array}$ & $\mathrm{NM}$ & $\begin{array}{l}\text { Building terms from } \\
\text { literature }\end{array}$ & $\begin{array}{l}\text { - Using OWL to design } \\
\text { ontology } \\
\text { - Using ontology to create } \\
\text { some assets for VR } \\
\end{array}$ & NM & $\begin{array}{l}\text { - Integrating ontology } \\
\text { inside VR to exchange } \\
\text { data, in an } \\
\text { interoperable way }\end{array}$ & $\begin{array}{l}\text { Ontology within VR } \\
\text { system was evaluated } \\
\text { through a case study }\end{array}$ \\
\hline $\begin{array}{l}\text { Elenius et } \\
\text { al. [23] }\end{array}$ & $\mathrm{NM}$ & $\begin{array}{l}\text { Selecting terms and } \\
\text { concepts from } \\
\text { articles }\end{array}$ & $\begin{array}{l}\text { - Using Flora code to design } \\
\text { ontology } \\
\text { - Using ontology as a reference } \\
\text { to develop some assets for VR }\end{array}$ & NM & $\begin{array}{l}\text { - Integrating ontology } \\
\text { inside VR to provide } \\
\text { reasoning }\end{array}$ & $\begin{array}{l}\text { All ontology models were } \\
\text { tested by SMEs }\end{array}$ \\
\hline $\begin{array}{l}\text { Liang et al. } \\
{[15]}\end{array}$ & $\mathrm{NM}$ & $\begin{array}{l}\text { Selecting terms and } \\
\text { concepts from } \\
\text { traditional Chinese } \\
\text { shadow }\end{array}$ & $\begin{array}{l}\text { - Using OWL to design } \\
\text { ontology } \\
\text { - Using ontology as a reference } \\
\text { to develop some assets for VR }\end{array}$ & NM & $\begin{array}{l}\text { - Integrating ontology } \\
\text { inside VR to support } \\
\text { ontology-based } \\
\text { retrieval, which } \\
\text { improves searching } \\
\text { performance } \\
\end{array}$ & $\begin{array}{l}\text { The feasibility verification } \\
\text { of ontology was } \\
\text { performed using user } \\
\text { experiences test }\end{array}$ \\
\hline $\begin{array}{l}\text { Yeh et al. } \\
\text { [13] }\end{array}$ & $\mathrm{NM}$ & NM & $\begin{array}{l}\text { - Using OWL to design } \\
\text { ontology } \\
\text { - Using ontology as a reference } \\
\text { to develop some assets for VR }\end{array}$ & NM & $\begin{array}{l}\text { - Integrating ontology } \\
\text { to support VR } \\
\text { presentations }\end{array}$ & NM \\
\hline $\begin{array}{l}\text { Dragoni et } \\
\text { al. [24] }\end{array}$ & $\mathrm{NM}$ & $\begin{array}{l}\text { Defining terms and } \\
\text { concepts by using } \\
\text { expert help }\end{array}$ & $\begin{array}{l}\text { - Using OWL to design } \\
\text { ontology } \\
\text { - Using ontology as a reference } \\
\text { to develop some assets for VR }\end{array}$ & NM & $\begin{array}{l}\text { - Using ontology to } \\
\text { describe the agent } \\
\text { behavioral script } \\
\text { - Testing the utility of } \\
\text { VR with ontology } \\
\end{array}$ & $\begin{array}{l}\text { Modelers, and developers } \\
\text { were interviewed to } \\
\text { evaluate the effectiveness } \\
\text { of the designed ontology- } \\
\text { based system. }\end{array}$ \\
\hline $\begin{array}{l}\text { Baldassini } \\
\text { et al. [12] }\end{array}$ & $\mathrm{NM}$ & $\begin{array}{l}\text { Using use cases to } \\
\text { select terms and } \\
\text { concepts }\end{array}$ & $\begin{array}{l}\text { - Using RDF and OWL to } \\
\text { design ontology } \\
\text { - Using ontology as a reference } \\
\text { to develop some assets for VR }\end{array}$ & NM & $\begin{array}{l}\text { - Implementing } \\
\text { ontology to retrieve } \\
\text { desired data about the } \\
\text { domain }\end{array}$ & $\begin{array}{l}\text { A number of healthy } \\
\text { subjects (from } 25 \text { to } 30 \\
\text { years old) were used to } \\
\text { test the ontology-based } \\
\text { system }\end{array}$ \\
\hline $\begin{array}{l}\text { Ramírez- } \\
\text { Fernández } \\
\text { et al. [25] }\end{array}$ & NM & $\begin{array}{l}\text { Selecting terms and } \\
\text { concepts from a } \\
\text { contextual study and } \\
\text { SLR }\end{array}$ & $\begin{array}{l}\text { - Using classes and OWL to } \\
\text { design ontology } \\
\text { - Using ontology as a reference } \\
\text { to develop some assets for VR }\end{array}$ & NM & $\begin{array}{l}\text { - To use ontology for } \\
\text { facilitating VE } \\
\text { development }\end{array}$ & $\begin{array}{l}\text { The evaluation was } \\
\text { implemented with } \\
\text { therapists and patients }\end{array}$ \\
\hline
\end{tabular}




\section{DISCUSSION}

The main objective of the study is to explore how ontology has been used to support VR development. Several ontologies have been proposed in the way to help the VR designing process. However, this review indicates that there is a general misuse on how to use ontology throughout all the stages of the methodology for VRT development. According to TABLE II, it is clear that most of the ontology engineers did not pay more attention to the assignment phase. Only a few studies had discussed about the scope and the objectives of ontology. However, they missed out on the inclusion of the ontology requirement specifications, which is as an agreement between the ontology engineer and the domain expert [27]. This approach enables the ontology engineer to include and exclude the most important concepts. Additionally, the involvement of domain experts is an essential part for knowledge acquisition; any lack of key experts can highly result in a partial model [11]. Domain experts should therefore be consulted in the earlier stages in order to avoid generating poor models which lack expressiveness, truthfulness, and details.

In the creation phase, most of the designed ontologies were represented using a tag or code. This approach breaks the Gruber's design criteria for ontology that suggests that the conceptualization should be represented at the knowledge level, which is free from any specific symbol-level encoding [8]. This kind of approach provides a good interaction among domain experts, the ontology team, and VR developers. This consequently conducts a better verification and validation process, since the ontology graphical model is frequently used to test the comprehensiveness of designed assets including 3D objects, scenarios, scripts and so on.

On the other hand, according to TABLE II, the test phase is totally missed. This evaluation is considered as an ex ant evaluation, which refers to evaluation of the prototype before the implementation stage. This is to avoid any kind of risk and effort before the design goes through construction [28]. Here the domain experts and VR developers verify whether the $3 \mathrm{D}$ graphical including scripts, scenarios and text, expressively reflect what is presented in ontology model. Thus, ignoring this phase can definitely lead to negative consequences such as conducting unnecessary redesigning or remodeling.

It can be seen from the above literature that ontology can play a significant role throughout all the stages of the methodology for VR development. It is, however, important to note the limitations of clearness on how ontology can go through all the stages. It may occur because, on one hand there is obvious missing or usage of immature methodology for designing ontology. On the other hand, it is the result of the lack of specific methodology of designing 3D modeling and VRT [29], [30], [31].

Over and above the latter shortages, it is difficult to guarantee the explicitness and truthfulness of training scenarios provided by VRT in the mentioned fields, because the ontology was missed or misused to be incorporated in all design phases of VR methodology. This could consequently raise high dangers in real life, especially when VRT is for areas involving trivial details that are important for saving lives. These sectors may include emergency response, healthcare, industry, army and so on.

\section{CONCLUSION}

Despite the great decision on selecting ontology as a tool to support VR development solutions, based on the review, there is still a problem of implementing this tool throughout all the phases of life cycle of VR development process in various domains. The major barrier preventing VRT from being fully adopted is that most solutions are immediate, designed only for the current perspective purpose, without applying an effective methodology that could facilitate the construction process to be faster, cost effective, and create expressive training scenarios with minimal mistakes.

As mentioned above, it is not clear how ontology plays a role throughout the life cycle of VRT design. TABLE III briefly shows the connection between phases of VR and stages of ontology development methodology. It provides an idea about how ontology can play a significant role to facilitate VR construction. Therefore, further research can be conducted in this way to systematically define the right methodology of designing VRT that can easily cooperate with the role of ontology.

This paper proposes a novel guideline to design VRT applications. This approach, provided in this research, aids on making VR implementations faster, enables reduction of the required time, and effectively creates semantic learning content and tarring scenario for safe VRT. Consequently, it significantly improves user outcomes and promotes the use of $\mathrm{VR}$ in training. 
TABLE III. CONNECTION BETWEEN METHODOLOGY FOR VR DEVELOPMENT AND ROLE OF ONTOLOGY

\begin{tabular}{|c|c|}
\hline Phases of VR Methodology & The Role of Ontology \\
\hline Assignment & $\begin{array}{l}\text { 1) The SMEs and ontology engineers work together in this phase. They make what is called ontology requirements specification } \\
\text { that serves as an agreement between SME and ontology engineering. These ontology requirements include: } \\
\text { - Define the goal and scope of designing ontology to be used in VR development. } \\
\text { - Define the intended end-users. } \\
\text { - Competency questions. }\end{array}$ \\
\hline Analysis & $\begin{array}{l}\text { 2) The answers to competency questions from SME and other relevant knowledge from (e.g., documents, observation) are } \\
\text { analyzed to get the foundation upon which the overall concept of the VR application is based in terms of requirements and wishes. } \\
\text { Actions include: } \\
\text { - Glossaries of terms } \\
\text { - List actions and objects derived from the extracted knowledge. } \\
\text { 3) The identified terms are not completely valuable as they exist in the current domain. Thus, they should be adjusted and } \\
\text { reengineered. Some actions comprise: } \\
\text { - Check and compare terms } \\
\text { - Identify shared knowledge } \\
\text { - Classify all objects - objects with similar or same functions and appearance. } \\
\text { - List all activities and interactions in another list. } \\
\text { - Define the states of objects. } \\
\text { - Assign actions to the objects. } \\
\text { - Draft the story board of the detailed scenario }\end{array}$ \\
\hline Creation & $\begin{array}{l}\text { 4) Designing the ontology becomes compulsory to guide designers through the rest of the VR's phases. } \\
\text { - Construct ontology model using visual modeling languages such as UFO and OntoUML } \\
\text { 5) This artifact serves as the major guidance to assist the VR developer to select the right objects, properties and level of detail } \\
\text { that he or she needs to represent by using multimedia modeling. }\end{array}$ \\
\hline Testing & $\begin{array}{l}\text { 6) Ontology is used as a tool to facilitate communication among team members } \\
\text { - Coordinated validation and verification are conducted by SME and IT experts to check the designed VR. } \\
\text { - Verify the level of connection between the designed VR to ontology model in terms of 3D graphical object, tasks, terms, } \\
\text { concepts and so on. }\end{array}$ \\
\hline Implementation & $\begin{array}{l}\text { 7) Transforming ontology from visual model to implementation helps VR development. Actions include: } \\
\text { - Provide reasoning process (e.g., decision making, student evaluation, retrieve information). } \\
\text { - Enhance interoperability. } \\
\text { 8) Conducting a test on the finished product. }\end{array}$ \\
\hline Operation & $\begin{array}{l}\text { 9) Use the artifact as a reference to compare the intended objectives with the observed result: } \\
\text { - The end users evaluate the utility of the artefact, for maintenance purposes, in order check any problems or difficulties. } \\
\text { - A meeting between VR designers and SMEs is held to discuss experiences learned from this project and to determine future } \\
\text { expansions of the ontology. }\end{array}$ \\
\hline
\end{tabular}

\section{ACKNOWLEDGMENT}

This research is supported by Transdisciplinary Research Grant Scheme (TRGS), Ministry of Higher Education (MOHE) and Universiti Kebangsaan Malaysia (UKM), Vot. No: TRGS/1/2020/UKM/02/6/2. We highly appreciate the enormous support received for this research project.

\section{REFERENCES}

[1] D. Bogusevschi, C. H. Muntean, and G.-M. Muntean, "Teaching and learning physics using 3D virtual learning environment: A case study of combined virtual reality and virtual laboratory in secondary school," J. Comput. Math. Sci. Teach., vol. 39, no. 1, pp. 5-18, 2020, [Online]. Available:

https://ezp.waldenulibrary.org/login?url=https://search.ebscohost.com/lo gin.aspx?direct=true $\& \mathrm{db}=$ edo $\& A N=142858119 \&$ site $=$ eds -

live\&scope $=$ site.

[2] C. W. Chang, S. C. Yeh, M. Li, and E. Yao, "The introduction of a novel virtual reality training system for gynecology learning and its user experience research," IEEE Access, vol. 7, pp. 43637-43653, 2019, doi: 10.1109/ACCESS.2019.2905143.

[3] M. Cook, Z. Lischer-Katz, N. Hall, J. Hardesty, J. Johnson, R. McDonald, and T. Carlisle, "Challenges and strategies for educational virtual reality: results of an expert-led forum on 3D/VR technologies across academic institutions," Inf. Technol. Libr., vol. 38, no. 4, pp. 2548, 2019, doi: 10.6017/ital.v38i4.11075.

[4] Y. Benferdia, M. N. Ahmad, M. Mustapha, H. Baharin, and M. Y. Bajuri, "Critical success factors for virtual reality-based training in ophthalmology domain," J. Heal. Med. Informatics, vol. 9, no. 3, pp. 114, 2018, doi: 10.4172/2157-7420.1000318.
[5] J. Radianti, T. A. Majchrzak, J. Fromm, and I. Wohlgenannt, "A systematic review of immersive virtual reality applications for higher education: Design elements, lessons learned, and research agenda," Comput. Educ., vol. 147, no. 2020, p. 103778, 2020, doi: 10.1016/j.compedu.2019.103778.

[6] U. H. Mohamad, M. N. Ahmad, Y. Benferdia, A. Shapi'i, and M. Y. Bajuri, "An overview of ontologies in virtual reality-based training for healthcare domain," Front. Med., vol. 8, no. July, pp. 1-13, 2021, doi: 10.3389/fmed.2021.698855.

[7] L. Olsina, "Analyzing the usefulness of thingFO as a foundational ontology for sciences," in Proceedings of ASSE'20, 49 JAIIO, 2020, pp. 1-20, doi: 10.13140/RG.2.2.15135.59043/1.

[8] T. R. Gruber, "A translation approach to portable ontology specifications," Knowl. Acquis., vol. 5, no. 2, pp. 199-220, 1993, doi: 10.1006/knac.1993.1008.

[9] D. Dermeval, J. Vilela, I.I. Bittencourt, J. Castro, S. Isotani, P. Brito, and A. Silva, "Applications of ontologies in requirements engineering: A systematic review of the literature," Requir. Eng., vol. 21, no. 4, pp. 405-437, 2016, doi: 10.1007/s00766-015-0222-6.

[10] S. Khantong and M. Ahmad, "An ontology for sharing and managing information in disaster response: In flood response usage scenarios," Data Semant., pp. 1-14, 2020, doi: 10.1007/s13740-019-00110-6.

[11] C. Feilmayr and W. Wöß, "An analysis of ontologies and their success factors for application to business," Data Knowl. Eng., vol. 101, no. 2016, pp. 1-23, 2016, doi: 10.1016/j.datak.2015.11.003.

[12] D. Baldassini, V. Colombo, D. Spoladore, M. Sacco, and S. Arlati, "Customization of domestic environment and physical training supported by virtual reality and semantic technologies: A use-case," in IEEE 3rd International Forum on Research and Technologies for Society and Industry (RTSI), Modena Italy : IEEE, 2017, pp. 1-6. 
[13] J. H. Yeh and X. M. Huang, "BkontoVr: A virtual reality exhibition system for biographic ontology-based semantic structure," in Proceedings of the 2018 2nd International Conference on Software and e-Business, S. Yang, and Y. Wang, Eds. Zhuhai,China:ACM, 2018, pp. 69-73, doi: 10.1145/3301761.3301775.

[14] K. Walczak, J. Flotyński, D. Strugała, S. Strykowski, P. Sobociński, A. Gałązkiewicz, F Górski, P Buń, P. Zawadzki, M. Wielgus, and R. Wojciechowski, "Semantic modeling of virtual reality training scenarios," in 17th EuroVR International Conference, EuroVR 2020, 2020, vol. 12499 LNCS, P. Bourdot, V. Interrante, R. Kopper, A.H. Olivier, H. Saito, G. Zachmann, Eds. Valencia, Spain: Springer, 2020, pp. 128-148, doi: 10.1007/978-3-030-62655-6_8.

[15] H. Liang, S. Deng, J. Chang, J. J. Zhang, C. Chen, and R. Tong, "Semantic framework for interactive animation generation and its application in virtual shadow play performance," Virtual Real., vol. 22, no. 2, pp. 149-165, 2018, doi: 10.1007/s10055-018-0333-8.

[16] M. Tielman, M. Van Meggelen, M. A. Neerincx, and W. P. Brinkman, "An ontology-based question system for a virtual coach assisting in trauma recollection," in 15th International Conference, IVA 2015, W.P. Brinkman, J. Broekens, D. Heylen, Eds. Delft, The Netherlands: Springer, 2015, pp. 17-27, doi: 10.1007/978-3-319-21996-7_2.

[17] J. Heyse, F. Ongenae, J. De Letter, A. All, F. De Bakcere, and F. De Turck, "Design of an ontology for decision support in VR exposure therapy," in 13th EAI International Conference on Pervasive Computing Technologies for Healthcare, J. Meyer, L, Eds. Mamykina. Trento, Italy: EAI, 2019, pp. 1-4, doi: 10.4108/eai.20-5-2019.2283493.

[18] P. E. Antoniou, E. Chondrokostas, C. Bratsas, P.-M. Filippidis, and P. D. Bamidis, "A medical ontology informed user experience taxonomy to support co-creative workflows for authoring mixed reality medical education spaces," in 7th International Conference of the Immersive Learning Research Network (iLRN). Eureka, CA, USA: IEEE, 2021, pp. $1-8$.

[19] A.-S. Dris, F. Lehericey, V. Gouranton, and B. Arnaldi, "OpenBIM based IVE ontology: An ontological approach to improve interoperability for virtual reality applications," in Advances in Informatics and Computing in Civil and Construction Engineering, I. Mutis, T. Hartmann, Eds. Chicago, United States: Springer, 2019, pp. 129-136, doi: 10.1007/978-3-030-00220-6_16.

[20] J. Beetz, J. Van Leeuwen, and B. De Vries, "IfcOWL: A case of transforming EXPRESS schemas into ontologies," Artif. Intell. Eng. Des. Anal. Manuf. AIEDAM, vol. 23, no. 1, pp. 89-101, 2009, doi: 10.1017/S0890060409000122.

[21] H. Vincent, J. Benoit, S. Xavier, and B. David, "Inoovas - industrial ontology for operation in virtual and augmented scene: The architecture," in Proceedings 2017 4th International Conference on Control, Decision and Information Technologies, CoDIT 2017. Barcelona, Spain: IEEE, 2017, pp. 300-305, doi: 10.1109/CoDIT.2017.8102608.

[22] F. T. Filho, Y. P. C. Aguiar, and M. D. F. Q. Vieira, "Ontology based modelling of operator training simulator scenarios from human error reports," in Proceedings of the 5th International Conference on
Simulation and Modeling Methodologies, Technologies and Applications (SIMULTECH-2015), M.S. Obaidat, J Kacprzyk, L. Ören, Eds. Setubal, Portugal: SCITEPRESS 2015, pp. 279-288, doi: $10.5220 / 0005543502790288$.

[23] D. Elenius, G. Denker, and M. Kim, "Semantically enhanced virtual learning environments using sunflower," in Research Conference on Metadata and Semantics Research, E. Garoufallou, I.S Coll, A. Stellato, J. Greenberg, Eds. Göttingen, Germany: Springer, 2016, vol. 672, pp. 81-93, doi: 10.1007/978-3-319-49157-8.

[24] M. Dragoni, C. Chidini, P. Busetta, M. Fruet, and M. Pedrotti, "Using ontologies for modeling virtual reality scenarios," in 12th European Semantic Web Conference, F. Gandon, M. Sabou, H. Sack, C. d'Amato, P. Cudré-Mauroux, A. Zimmermann, Eds. Portoroz, Slovenia: Springer, 2015, vol. 9088, pp. 575-590, doi: 10.1007/978-3-319-18818-8.

[25] C. Ramírez-Fernández, E. García-Canseco, A. L. Morán, and J. R. Gómez-Montalvo, "Evaluation results of an ontology-based design model of virtual environments for upper limb motor rehabilitation of stroke patients," in Proceedings of the 3rd 2015 Workshop on ICTs for improving Patients Rehabilitation Research Techniques, H.M Fardoun, P. Gamito, V.M.R Penichet, D.M Alghazzawi, Eds. Lisbon, Portugal: Association for Computing Machinery, 2015, pp. 105-108, doi: 10.3414/ME16-02-0017.

[26] J. Polcar, M. Gregor, P. Horejsi, and P. Kopecek, "Methodology for designing virtual reality applications," in Proceedings of the 26th DAAAM International Symposium. Vienna, Austria: DAAAM International Vienna, 2015, pp. 768-774, doi: 10.2507/26th.daaam.proceedings.107.

[27] M. C. Suárez-Figueroa, A. Gómez-Pérez, and B. Villazón-Terrazas, "How to write and use the ontology requirements specification document," in OTM Confederated International Conferences" On the Move to Meaningful Internet Systems", R. Meersman. T. Dillon, P. Herrero, Eds. Vilamoura, Portugal: Springer, 2009, vol. 5871 LNCS, pp. 966-982, doi: 10.1007/978-3-642-05151-7_16.

[28] J. Venable, J. Pries-Heje, and R. Baskerville, "FEDS: A Framework for evaluation in design science research," Eur. J. Inf. Syst., vol. 25, no. 1, pp. 77-89, 2016, doi: 10.1057/ejis.2014.36.

[29] T. D. Parsons, T. Bowerly, J. G. Buckwalter, and A. A. Rizzo, "A controlled clinical comparison of attention performance in children with ADHD in a virtual reality classroom compared to standard neuropsychological methods," Child Neuropsychol., vol. 13, no. 4, pp. 363-381, 2007, doi: 10.1080/13825580600943473.

[30] P. B. L. Klavdianos, M. Parente, L. M. Brasil, and J. M. Lamas, "ONTO-MAMA: An unified ontology and 3D graphic model of the female breast anatomy," in Proceedings ofthe International Conference on Health Informatics (HEALTHINF-2012). Vilamoura, Algarve: SciTePress, 2012, pp. 106-116, doi: 10.5220/0003796401060116.

[31] J. Dascal, M. Reid, W.W, Ishak, B. Spiegel, J. Recacho, B. Rosen, and I. Danovitch, "Virtual reality and medical inpatients: A systematic review of randomized, controlled trials," Innov. Clin. Neurosci., vol. 14, no. 12, pp. 14-21, 2017. 